\title{
The Potential for Citizen Science to Improve the Reach of Sanitary Inspections
}

\author{
Jo Herschan ${ }^{1, *}$, Richard King ${ }^{1}\left(\mathbb{D}\right.$, Theresa Mkandawire ${ }^{2}$, Kenan Okurut ${ }^{3}$, Dan J. Lapworth ${ }^{4}$ \\ Rosalind Malcolm ${ }^{5}$ and Katherine Pond ${ }^{1}$ \\ 1 Centre for Environmental Health and Engineering (CEHE), Department of Civil and Environmental \\ Engineering, University of Surrey, Guildford, Surrey GU2 5XH, UK; r.a.king@surrey.ac.uk (R.K.); \\ k.pond@surrey.ac.uk (K.P.) \\ 2 Department of Civil Engineering, University of Malawi-The Polytechnic, Private Bag 303, \\ Blantyre 312225, Malawi; tmkandawire@poly.ac.mw \\ 3 Department of Civil and Building Engineering, University of Kyambogo, Kyambogo Road, \\ Kiwatule—Banda, Kampala, Uganda; ken_okurut@yahoo.com \\ 4 British Geological Survey, Wallingford OX10 8BB, UK; djla@bgs.ac.uk \\ 5 School of Law, University of Surrey, Guildford, Surrey GU2 5XH, UK; r.malcolm@surrey.ac.uk \\ * Correspondence: j.herschan@surrey.ac.uk
}

Received: 30 October 2020; Accepted: 4 December 2020; Published: 6 December 2020

check for updates

\begin{abstract}
To achieve Sustainable Development Goals (SDGs) 6, universal and equitable access to safe and affordable drinking-water quality and sanitation for all, and 10, to reduce inequality within and among countries, additional and urgent work is required. Efforts to achieve these Goals in the context of small drinking-water supplies, which are the furthest behind in regards to progress, are of particular need. Reasons for this disparity in progress include the remoteness of access to small drinking-water supplies and the lack of technical and financial capacity for monitoring supplies. The World Health Organization promote the use of Sanitary inspection (SI) as an on-site assessment of risk. Despite the potential to increase the body of knowledge and information on supplies in a region, there has been limited research into the role of citizen science and SIs. To meet SDG targets, we need to improve the reach of SIs. This study uses a mixed methods approach of quantitative on-site SI data collection and remote SI data collection via photographic images, together with qualitative data collection, collected by non-expert students, who are citizens of Malawi, as well as a panel of experts in the field of SI. Results indicate that, although further research into the topic is required prior to widescale implementation, the potential exists for citizens to conduct SI, with remote expert verification of the results using photographic images of supplies. Further documentation or guidance is required to support citizens in this process. The results highlight a critical gap in the availability of appropriate documentation for unprotected spring sources which is urgently required. The use of citizen science for SI data collection is in its infancy. However, this study indicates that there is potential to explore the use of citizen science in this area, which will contribute to achieving SDGs 6 and 10 .
\end{abstract}

Keywords: citizen science; drinking-water quality; photographic sanitary inspection; remote sanitary inspection; risk assessment; risk management; sanitary inspection

\section{Introduction}

Target 6.1 of Sustainable Development Goal (SDG) 6 aims to achieve access to safe and affordable drinking-water for all by 2030 [1]. The target is tracked with the indicator of "safely managed drinking-water services"-drinking-water from an improved water source that is located on premises, 
available when needed, and free from faecal and priority chemical contamination. The 2020 SDG progress report indicates that "unless current rates of progress increase substantially, Goal 6 targets will not be met by 2030" [2].

The World Health Organization (WHO) recommends that water quality testing and risk assessment be undertaken as complementary activities to identify sources and pathways of potential contamination and to verify the quality of drinking-water supplies [3]. Water quality testing, although important for verification purposes, provides retrospective information on the quality of a supply [4] and requires physical and financial resources, which small supplies often have limited access to. As a result, testing is not routinely, if ever, done in many settings globally [5], and the reliance on risk-based approaches for surveillance purposes are even greater. This is reflected by the risk-based approach increasingly being adapted into drinking-water management legislation [6]. One approach to risk assessment of drinking-water supplies is the use of sanitary inspections (SIs). Defined by the WHO as an "on-site inspection and evaluation by qualified individuals of all conditions, devices and practices in the water-supply system that pose an actual or potential danger to the health and well-being of the consumer" [7], SIs provide a low-cost, easy-to-use monitoring approach that is particularly suited to small drinking-water supplies and settings with limited resources and/or capacity [8].

Though different versions of SI forms with alternative questions and scoring methods exist [9], the WHO [7] suite of forms is the most widely used. Consisting of a list of equally weighted "Yes/ $\mathrm{No}^{\text {" }}$ questions that indicate the presence or absence of observable contaminant pathways; actual and potential sources of contamination; and breakdowns in barriers to contamination [10], the output of the WHO SI forms is calculated by tallying the number of identified risk factors at a supply to provide a sanitary risk score. This risk score is then used to categorize the level of risk at the supply from "low" to "very high".

Though WHO recommends that SIs should be carried out by "qualified individuals" [7], a recent qualitative study [8] discussed a main benefit of SIs to be their ease-of-use for lay people. SIs by potentially less qualified or inexperienced individuals are more likely to be undertaken at small drinking-water supplies, typically owing to a lack of available professionals to undertake these activities. Such personnel shortages may be attributed to the resource challenges frequently associated with small drinking-water supply management [11], or to surveillance agencies being overwhelmed by large numbers of small supplies which tend to be spread sparsely over vast, often geographically remote, areas. There has been limited research into SI result accuracy and consistency between inspectors with varying levels of experience (from novice to experienced professional) and training [12-14] with no studies identified into the use of citizens for SI. In comparison with more definite indicators that water quality results provide, the measure of consistency of SI risk scores is noted as one of the challenges with regards to the use of the form [12].

An SI undertaken by a non-professional is effectively citizen science, a practice whereby members of the general public participate in science as researchers or data collectors [15]. Though citizen science has been used in several sectors [16-19], and even for monitoring SDGs [20], it is most prevalent within the environmental sector to study climate and ecosystems [21,22] and has been used in coastal settings since the late 1990s [23]. General advantages of citizen science implementation include increased scientific literacy [24] and engagement within the public [25]; cost-effective data collection [26]; and completion of required remedial actions that may otherwise by ignored due to resource constrictions [27]. The main challenges surrounding citizen science are a lack of volunteer interest [26]; issues with data fragmentation and inaccuracy [28]; and uncertainty from professionals regarding the quality of data collected by citizens [29].

In recent years, citizens have been recruited to undertake sampling and testing of waterways [30-32] and drinking-water supplies [33]. Despite the increased use of citizens in the collection of water quality data, to our knowledge, only one study has used citizens to collect information on risks to drinking-water supplies [34]. The findings of this study, which was based in Malawi, recommended 
further testing of the citizen science approach to build capacity for monitoring risks relating to water, sanitation and hygiene.

Some sectors have used collaborations between citizen scientists and remote professionals [35], though no evidence was identified that examined the potential for citizens to cooperate with remotely based professionals to complete drinking-water risk assessments.

The WHO SI forms are currently being updated to make them more robust; reflect appropriate technologies alongside current best practice technical and management advice; and better align with the Water Safety Planning (WSP) methodology. The aim of this paper is to investigate the potential role of citizen science in the field of SI with remote validation of results by experts in SI. A mixed methods approach was used to answer the following questions:

(i) Is there consistency between citizen's perception of risk to small drinking-water supplies?

(ii) Do citizen's perception of risk change with the number of inspections conducted?

(iii) Do citizens require additional information to survey supplies effectively?

(iv) Do citizens assign comparative risk scores when surveying supplies on-site and remotely using photographic images?

(v) Is it possible to verify responses remotely using expert judgement?

It is anticipated that the findings of this study will contribute to achieving SDG Target 6.1 by suggesting an approach which will increase the reach of SIs in small drinking-water supplies through the use of citizens.

\section{Materials and Methods}

\subsection{Citizen Selection}

Data were collected, in three sequential study phases, by 24 undergraduate students from University of Malawi-The Polytechnic. The undergraduate students were in the first to the fifth year of various degrees, though the majority (66\%) studied Civil Engineering, majoring in Transport, Structures or Water. Table 1 provides the breakdown of the number of students who participated in each study per subject. While the majority of the students had some experience of the rural settings visited during the studies, having either worked in, lived in or visited such locations, their professional experience of working with SIs was extremely limited. Participation was voluntary. Although a quarter of the students were majoring in Water Engineering, therefore indicating an interest in the broader topic of drinking-water, the collective limited experience of working with SIs, the diversity in personal and educational backgrounds, and the voluntary nature of their participation qualified the students to be classed as members of the general public, thus participating as citizen scientists in this study. The students will herein be described as citizens.

Table 1. Number of participants per degree subject per study.

\begin{tabular}{ccc}
\hline Undergraduate Subject & $\begin{array}{c}\text { No. Citizens Who Participated in Each Study } \\
\text { Studies } \mathbf{1} \text { \& 2 }\end{array}$ & $\begin{array}{c}\text { Study 3 } \\
\text { Auditing }\end{array}$ \\
\hline Business Communication & 2 & 0 \\
Civil Engineering (Structures) & 5 & 0 \\
Civil Engineering (Transport) & 5 & 3 \\
Civil Engineering (Water) & 6 & 3 \\
Environmental Science & 2 & 5 \\
Physical Planning & 1 & 1 \\
Technical Education & 2 & 1 \\
\hline
\end{tabular}

Prior to commencing the fieldwork, the citizens received a one-hour presentation which included a summary of the purpose of the study, background to the concept of SIs and the risk management 
approach to water safety, and information on the update to the WHO SI forms. Sample borehole and spring SI forms were shared with the citizens without any technical explanations. The participants were instructed to inspect supplies as individuals, without conferring with each other, to ensure the results were representative of the individual's perception of risk. These instructions were reiterated throughout the fieldwork.

Materials used for data collection were the modified WHO borehole SI form and the published spring SI form (see Supplementary Materials) [36], a pen or pencil, and a camera. The Internet was used to circulate and gather the follow-up questionnaire data in Study 3. The citizens were provided with the SI forms but already had access to a writing implement, a camera via their mobile phones and the Internet.

\subsection{Fieldwork Location}

Fieldwork was carried out in December 2019, in and around Ntcheu District of Malawi's Central Region. Bordering eastern Mozambique, Ntcheu District is located approximately halfway between Malawi's capital city, Lilongwe, and its second largest city, Blantyre. Figure 1 provides a map of the study location and supplies studied. The District has been subject to severe water quantity challenges due to source water shortages at the Mpira Dam which, until recent years, was one of the biggest water sources in the region [37]. As a result, there has been a focus on rehabilitation and drilling of new boreholes in the region to meet the demand for drinking-water [38].

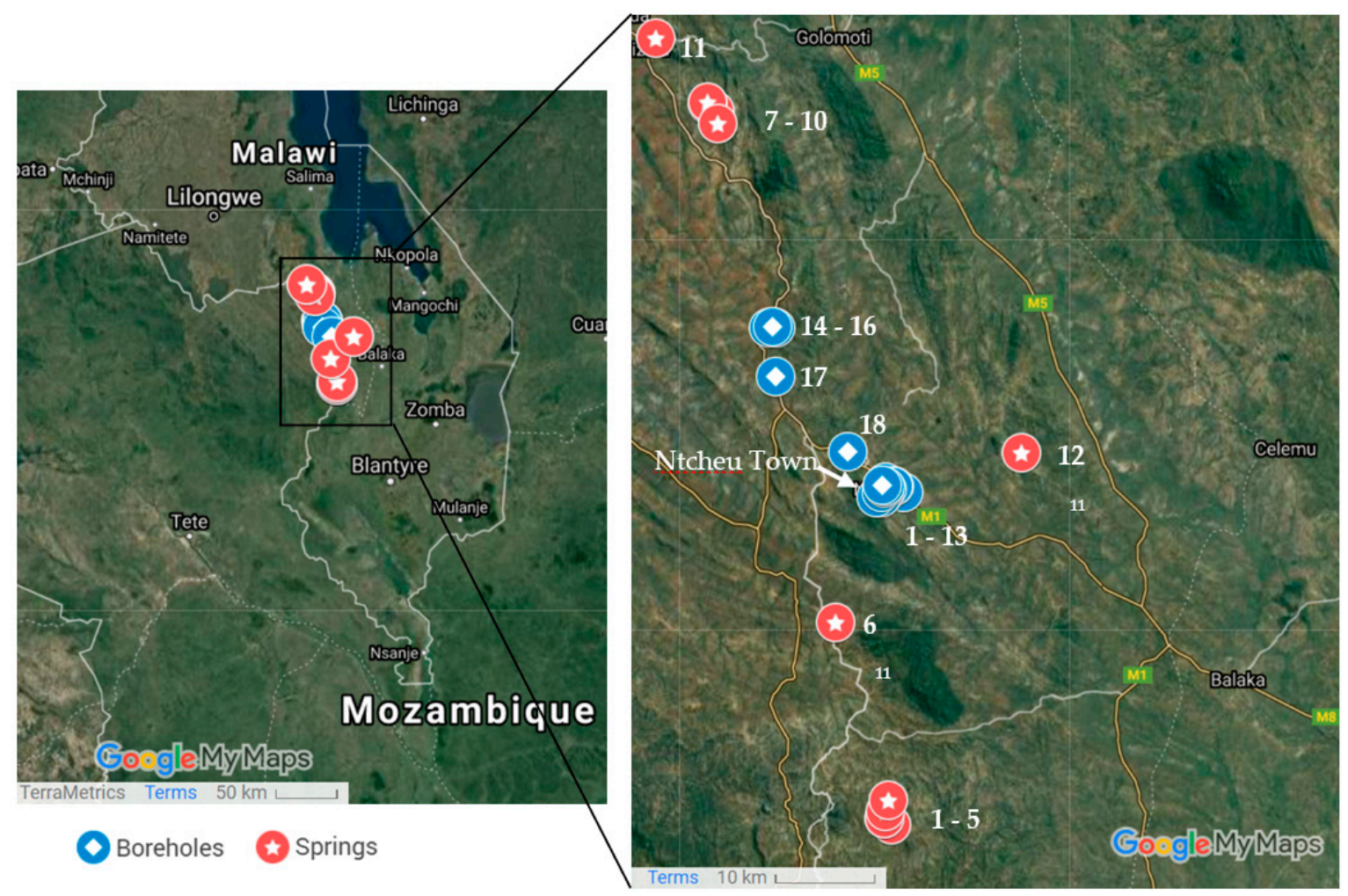

Figure 1. A map of the borehole and spring supplies, including the numbers assigned to each supply, surveyed during fieldwork (created using GoogleMaps $2020^{\mathrm{TM}}$ ).

The citizens travelled to the supplies under inspection as one group and were provided the same length of time to inspect each supply. All data were collected during the same week in which weather conditions were warm and dry, so corrections for seasonal variation were not required. 


\subsection{Study 1: SIs-Borehole Supplies}

In total, 18 operational and accessible handpump borehole supplies were identified by Water Officers from the Ntcheu Office of the Ministry of Irrigation and Water Development. The boreholes were inspected in succession, with Supply 1 being the first and Supply 18 the last. A prototype borehole SI form that is currently being developed by the WHO was used in this study. SI questions were designed using both the traditional "Yes/No" answer type and the risk level assignment answer type (e.g., No, Low, Medium, High) which is commonly utilised in WSPs.

Supplies 1-13 were in the rural areas directly surrounding the town of Ntcheu. Supplies 14-18 were in more remote, harder to access, locations to the north of the town of Ntcheu. See Figure 1 for a map of the borehole locations.

\subsection{Study 2: SIs—Spring Supplies}

In total, 12 spring supplies were identified by Water Officers from the Ntcheu District Water Office. Due to the nature of spring sources, the spring supplies were spread over a wider geographical area and were situated in more inaccessible locations than the borehole supplies (see Figure 1). These access limitations resulted in half of the citizens, unexpectedly, being unable to access, and therefore inspect, the first six spring sources.

The recently published spring SI form, which was developed by the WHO, was used in this study. The form also uses both the traditional "Yes/ $\mathrm{No}^{\prime}$ answer type and the risk level assignment answer type (e.g., No, Low, Medium, High) that is commonly utilised in WSPs.

\subsection{Study 3: Photographic SI of Supplies}

To investigate the potential for SIs to be conducted remotely, using photographic images, the citizens were asked to reinspect a selection of the supplies using photographic images. A total of five experts were asked to conduct the same photographic inspection to verify the citizens results. This remote method of SI will herein be referred to as photographic inspection.

The SI datasets collected during Studies 1 and 2 were analysed to identify which borehole and spring supplies were perceived, on average, by the citizens as the highest risk (borehole supply 3 , spring supply 3), and lowest risk (borehole supply 14, spring supply 10). A series of photographic images of these supplies, along with the first and last supply of each type inspected (borehole supplies 1 and 18, spring supplies 1 and 12), were compiled and provided to the citizens.

The citizens were provided with blank copies of the same borehole and spring SI forms used during Studies 1 and 2, to survey the images. Table 2 denotes what each question relates to-a copy of the original forms is provided in the Supplementary Materials.

Questions 7 and 9 of the borehole form and questions 9 and 11 of the spring form were removed from these blank forms as the questions were out of range of the image provided (refer to Supplementary Materials). A column was added to state 'Unable to answer from image' should the student feel they could not assess any of the remaining questions by photographic inspection.

To allow sufficient time for citizens memories relating to supply characteristics to fade, images were circulated to the citizens for photographic inspection nine months after the fieldwork study. This lapse in time, and subsequent risk of non-responses, was identified as a research risk at the outset. Responses from citizens were collated and analysed for correlation between remote and in-person inspection results.

Alongside the photographic SI, citizens were asked some more detailed questions regarding their background working or living in rural settings, how their perception of risk and preparedness to assess risk changed throughout the study and which questions they perceived as either easier or more difficult to answer. 
Table 2. Summary of the questions on each form (see Supplementary Materials for a copy of the full forms).

\begin{tabular}{ccc}
\hline Question No. & Borehole Form & Spring Form \\
\hline Q1 & Damaged or loose pump & $\begin{array}{c}\text { Missing or inadequate protective wall or spring } \\
\text { box structure }\end{array}$ \\
\hline Q2 & Damaged or unsanitary borehole seal & Unclean or inadequately positioned outlet pipe \\
\hline Q3 & Absent or inadequate apron & Eroded or prone to erosion backfill area \\
\hline Q4 & Inadequate drainage & Inadequate drainage \\
\hline Q5 & Absent or inadequate fencing & Missing or inadequate storm water diversion ditch \\
\hline Q6 & Sanitation within $10 \mathrm{~m}$ & Absent or inadequate fencing to prevent animals \\
\hline Q7 & Sanitation within $30 \mathrm{~m}$ & Absent or inadequate fencing to prevent other \\
contaminants
\end{tabular}

The same photographic images circulated to the citizens were also circulated to five experts in the field of SI, for remote validation of risk level. Three experts were asked to survey the borehole supplies and two experts were asked to survey the spring supplies. The experts were selected for their experience in undertaking SIs on small supplies. To ensure there was no bias in the results and that risks were assigned purely on the basis of the photographs provided, the experts were not provided with any specific information about the supplies, such as location.

\subsection{Data Analysis}

Data were analysed using a combination of the R Programme [39] and Microsoft Excel packages to interrogate the research questions.

\subsection{Research Ethics}

The University of Surrey Self-Assessment for Governance and Ethics (SAGE) tool was used to confirm that, as outlined by the University of Surrey Research Ethics Committee, ethics approval was not required for the qualitative data collection.

\section{Results}

\subsection{The Presence of Risk, i.e., Trends in "Yes" and "No" Responses, Assigned per Citizen Using Borehole Data}

Every citizen noted the presence of at least one risk at every supply. Figure 2 provides the total number of risks assigned for all citizens for all supplies per question number. Question 5 was the most frequently identified risk, followed by questions 8, 3, 4 and 7. Questions 1, 2, 6 and 9 were answered "Yes" noticeably less frequently.

The cohort assigned fewer risks to supplies 11-18 than supplies 1-10. This does not correlate with the change in study area. 


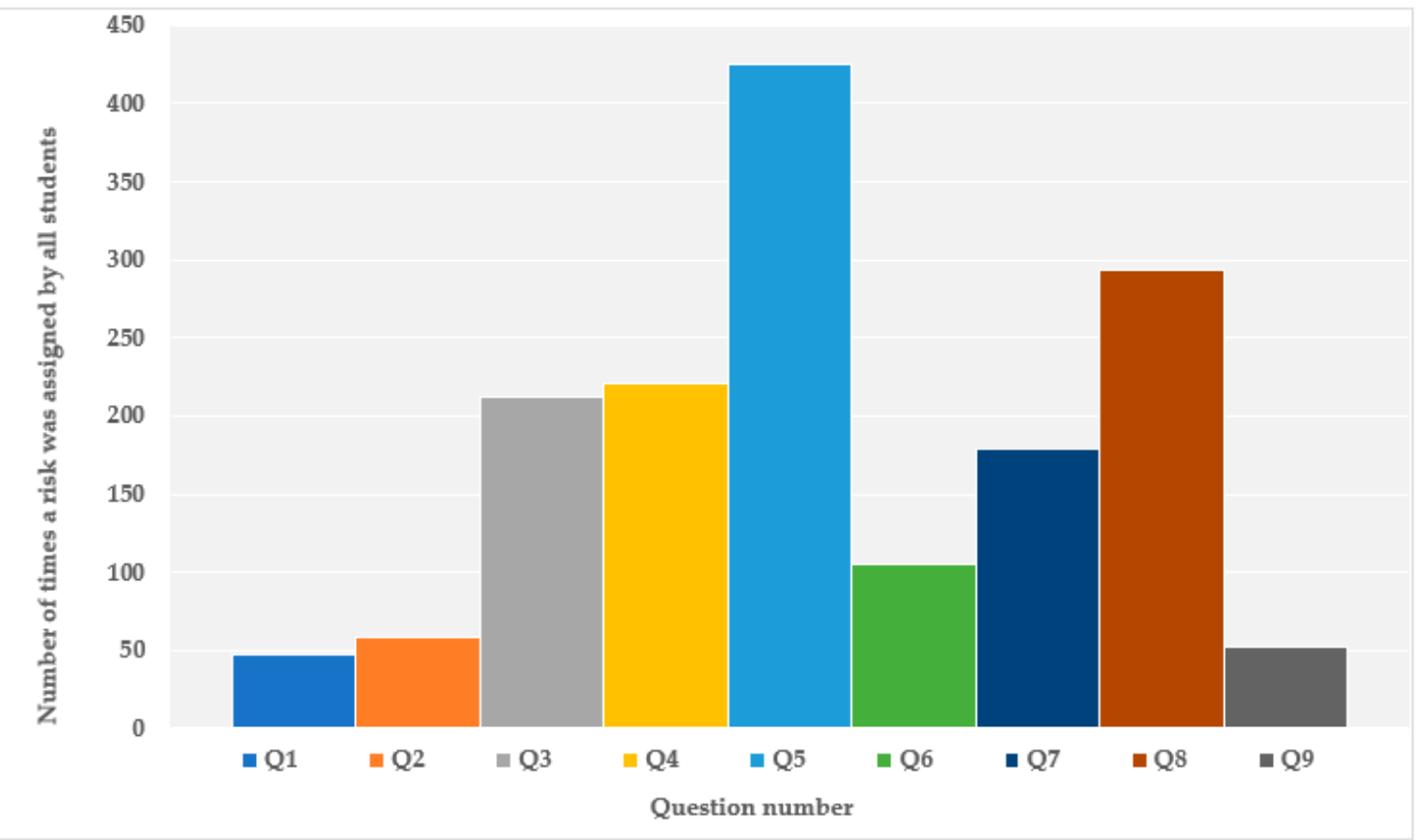

Figure 2. Number of times a risk was assigned for all borehole supplies per question.

\subsection{Risk Level Assigned per Citizen Subject}

SI risk scores assigned by the citizens were calculated for every borehole supply and grouped by citizen degree subject. The average risk scores for each citizen degree subject, per supply, is provided in Figure 3. The ANOVA test was used to identify any statistically significant differences. The results indicated a relationship between the different degree subjects and the average risk score assigned, and that risk perception did vary with the subject that the citizens were studying, $F(7,136)=8.12$, Fcrit $(7,136)=2.08, p=3.07 \times 10^{-8}$. The null hypothesis can be rejected. An alpha level of 0.05 was used for the statistical tests.

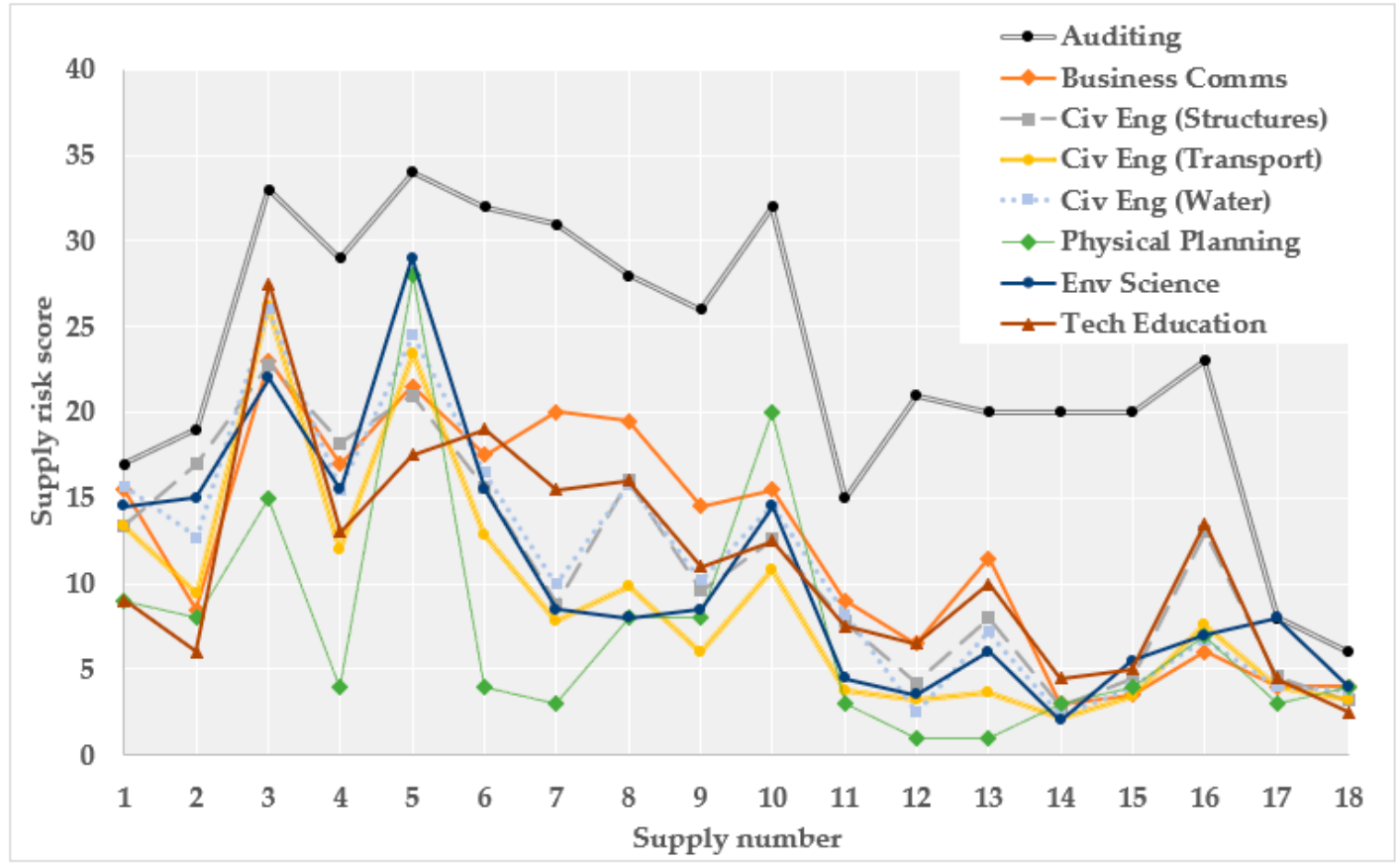

Figure 3. Average supply risk score as assigned per citizen degree subject. 
The two outliers follow the same trend as for the number of risks assigned. The individual studying Auditing perceived risks to be far higher than the rest of the cohort while the individual studying Physical Planning student generally perceived risks to be lower than the other subjects, although to a lesser degree from supply 11 onwards.

The ANOVA test was also applied to assess the range of citizen responses within each subject per borehole supply. The two subjects which only had one citizen (Auditing and Physical Planning) were omitted from this calculation. Results indicated that there was a relationship between the range in risks assigned and the actual risk score attributed provided, $F(5102)=6.46$, Fcrit $(5102)=2.30, p=2.93$ $\times 10^{-5}$. An alpha level of 0.05 was used for the statistical tests. The null hypothesis can be rejected. The range of risk scores per degree subject (Figure 4) indicates that in several instances, the higher the average supply risk score, the greater the range in risk score. Additionally, the range of attributed risk scores is not dependent on the number of citizens within each degree discipline. For instance, although there were a larger number of citizens for each of the civil engineering disciplines, the range of risks assessed was not greater.

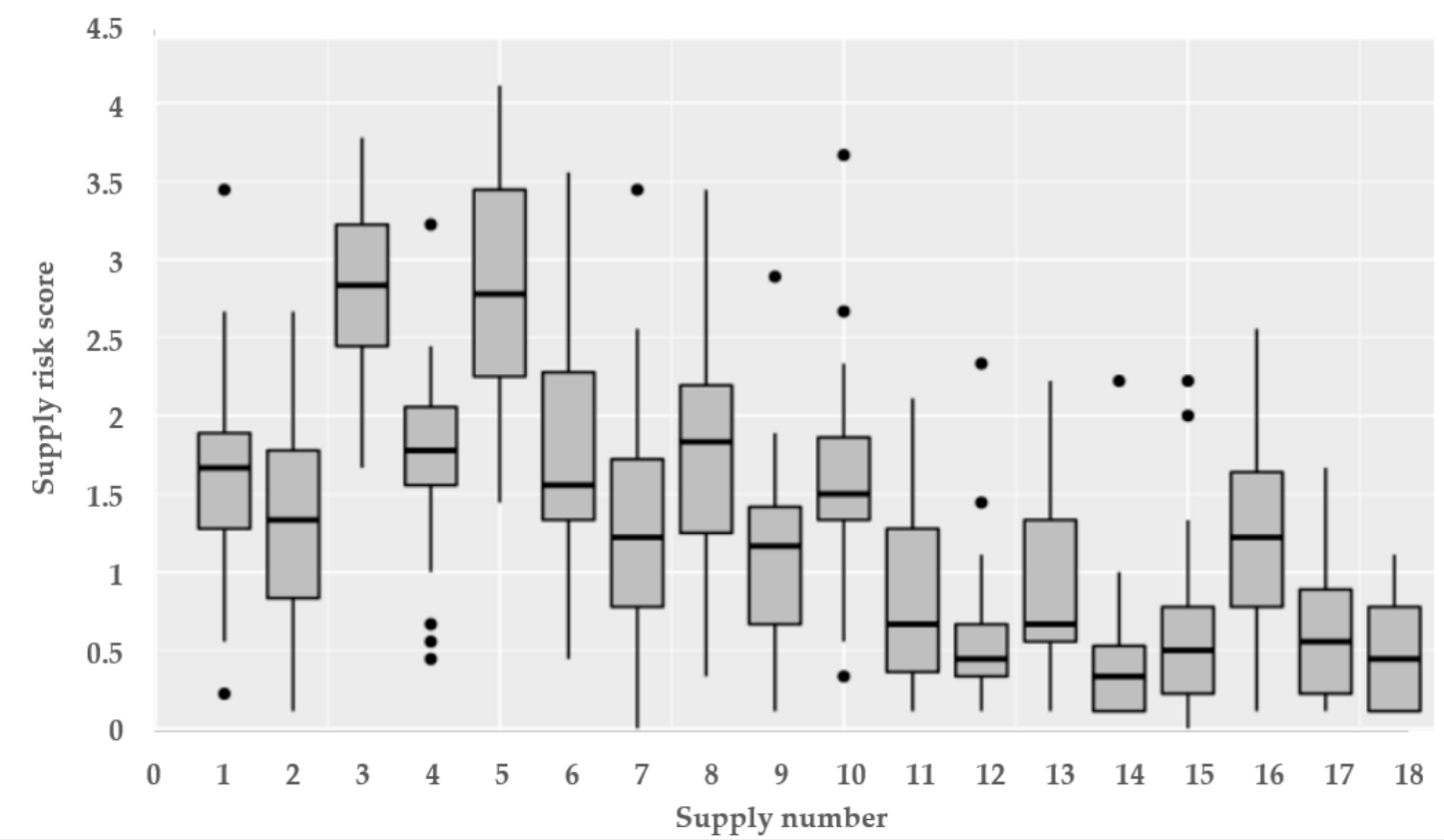

Figure 4. The median, inter-quartile range, minimum and maximum supply risk scores, as assigned by all citizens, for each per supply.

\subsection{Variation in Response Trends with Borehole Study Progression}

The dispersions of the total risk scores assigned by the citizens to each borehole supply is provided in Figure 4. There was a moderate, negative correlation between supply number and the average risk score assigned to a supply, $p=<2.2 \times 10^{-16}, \rho=0.60$. There was also a moderate, negative correlation between the supply number and the deviation of risk scores assigned by citizens for each supply, $p=<2.2 \times 10^{-16}, \rho=0.48$. Therefore, as the study progressed, the average SI score assigned by the citizens decreased, but so did the spread of risk scores.

This change in risk was reflected by the results of the questionnaires in which 10 out of the 14 respondents $(71 \%)$ felt that their perception of risk did change to some degree throughout the study with an increase in preparedness to assess risk. Figure 5 indicate the citizen's preparedness to assess risk at the beginning and the end of Study 1. 


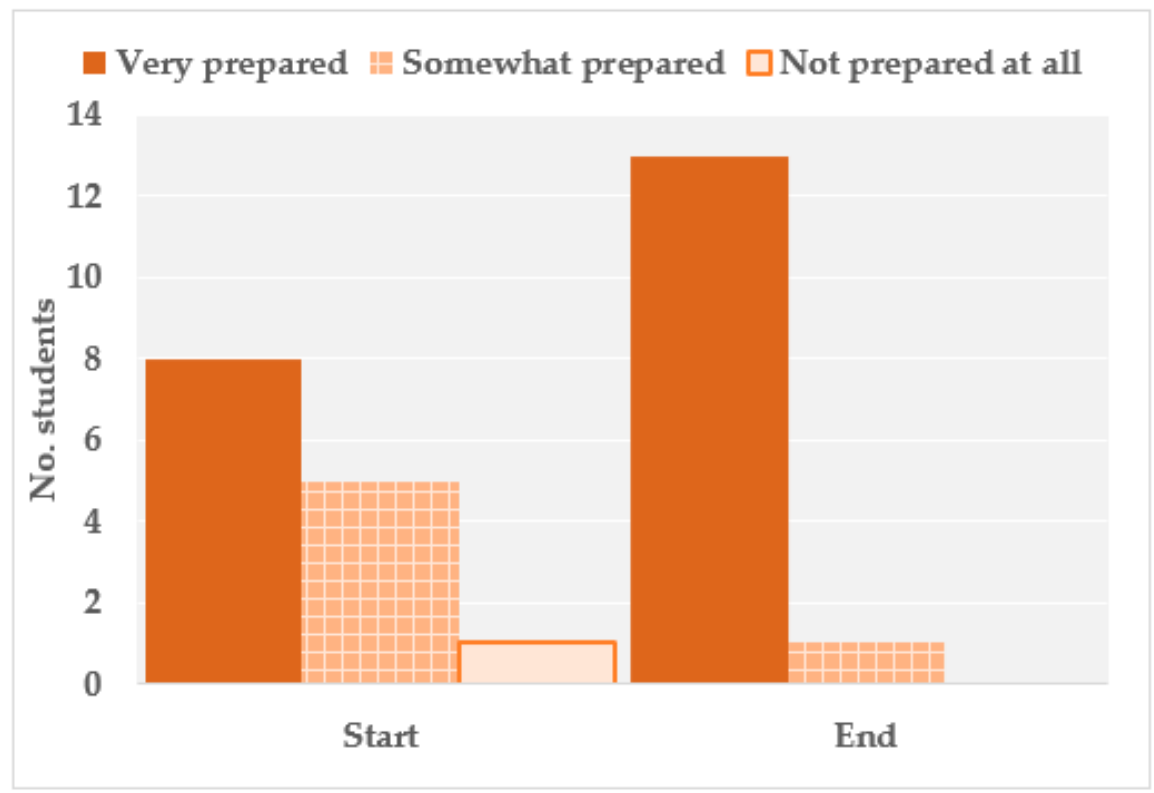

Figure 5. Preparedness to assess risk at the start and end of Study 1.

\subsection{Variation in Borehole SI Response per Question Number}

The sum frequency of risk levels assigned for all supplies per SI question is provided in Table 3. From this table it is evident that risks were assigned to Question 5 most frequently, followed by Questions 8, then 3 and 4 (see also Figure 3).

Table 3. Risk levels assigned for each question number and the easiest and hardest questions to answer as ranked by the citizens (denotes no responses).

\begin{tabular}{cccccccccc}
\hline & Q1 & Q2 & Q3 & Q4 & Q5 & Q6 & Q7 & Q8 & Q9 \\
\hline No risk & 385 & 374 & 222 & 211 & 6 & 326 & 254 & 137 & 379 \\
\hline Low & 17 & 27 & 64 & 54 & 102 & 20 & 56 & 105 & 16 \\
\hline Medium & 18 & 19 & 79 & 70 & 118 & 40 & 78 & 126 & 26 \\
\hline High & 12 & 12 & 67 & 97 & 206 & 46 & 44 & 64 & 11 \\
\hline Easiest to answer & 3 & 1 & 3 & 4 & 8 & 2 & 2 & - & - \\
\hline Hardest to answer & 1 & 4 & 2 & - & - & 3 & 3 & - & - \\
\hline
\end{tabular}

During Study 3, citizens were asked to rank which question(s) they found easiest and hardest to assign risk scores to. Results are included in Table 3.

\subsection{Variation in Responses per Supply Type}

Results of the spread of risks assigned for all supplies, broken down by subject for boreholes and springs are provided in Figure 6. Results indicate a similar trend for boreholes and springs. Most citizens exhibited a similar mean score to each other, for both boreholes and springs, with the exception of the individual studying Auditing, who attributed far higher risks than the rest of the cohort. 


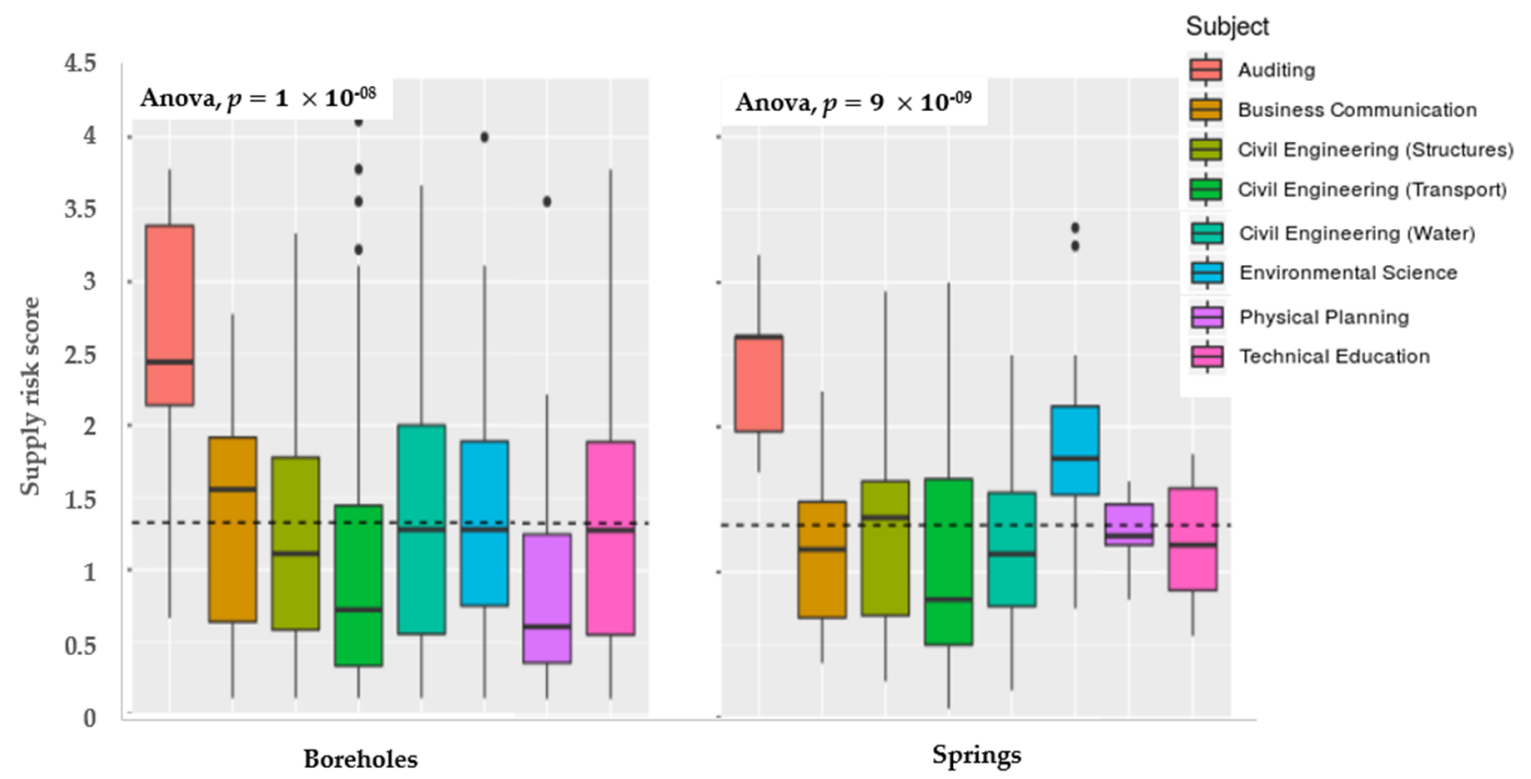

Figure 6. Total supply scores for all supplies per degree subjects studied (boreholes on the left and springs on the right).

The spread of risk scores assigned per degree subject was greater for boreholes than for springs. This was not affected by the number of citizens within an individual subject category. For instance, the largest group of citizens (6) by subject was Civil Engineering (Water), however this group had one of the smallest deviations for spring supplies.

Half of the citizens from Study 3 stated that they found both supply types equally easy to identify hazards with three and four citizens finding it easier to identify hazards associated with springs or boreholes, respectively. In total, 8 out of the 14 citizens found both supply types equally easy to assign risk scores to, with three and four citizens stating that springs or boreholes were easier to assign risk scores to, respectively.

\subsection{Correlations between On-Site and Photographic Inspections and Comparison with Expert Responses}

The two experts who participated in the photographic spring inspection raised several questions around the validity of the forms use for the four spring supplies. They queried that the supplies are unprotected springs and that therefore the forms were not applicable to the sources. Due to these queries which were raised by the experts, discussed further in the Discussion, the following results relate only to the borehole photographic inspections.

The overall supply risk assigned by the citizens for each of the borehole supply during the on-site and photographic inspection is provided in Figure 7. The Spearman's rank correlation coefficients, calculated for the citizen responses, as provided in Table 4, indicate that correlation between the on-site and photographic surveys varied between moderate correlation, weak correlation to very weak correlation. Removal of one or two outlying responses for each supply (citizen 13 from the supply 1 calculation and the removal of citizens 1 and 6 from supply 18 and 14 calculations) indicate that these correlation coefficients are greatly influenced by just one or two outlying citizens and actually there was strong correlation between the on-site and photographic surveys. 

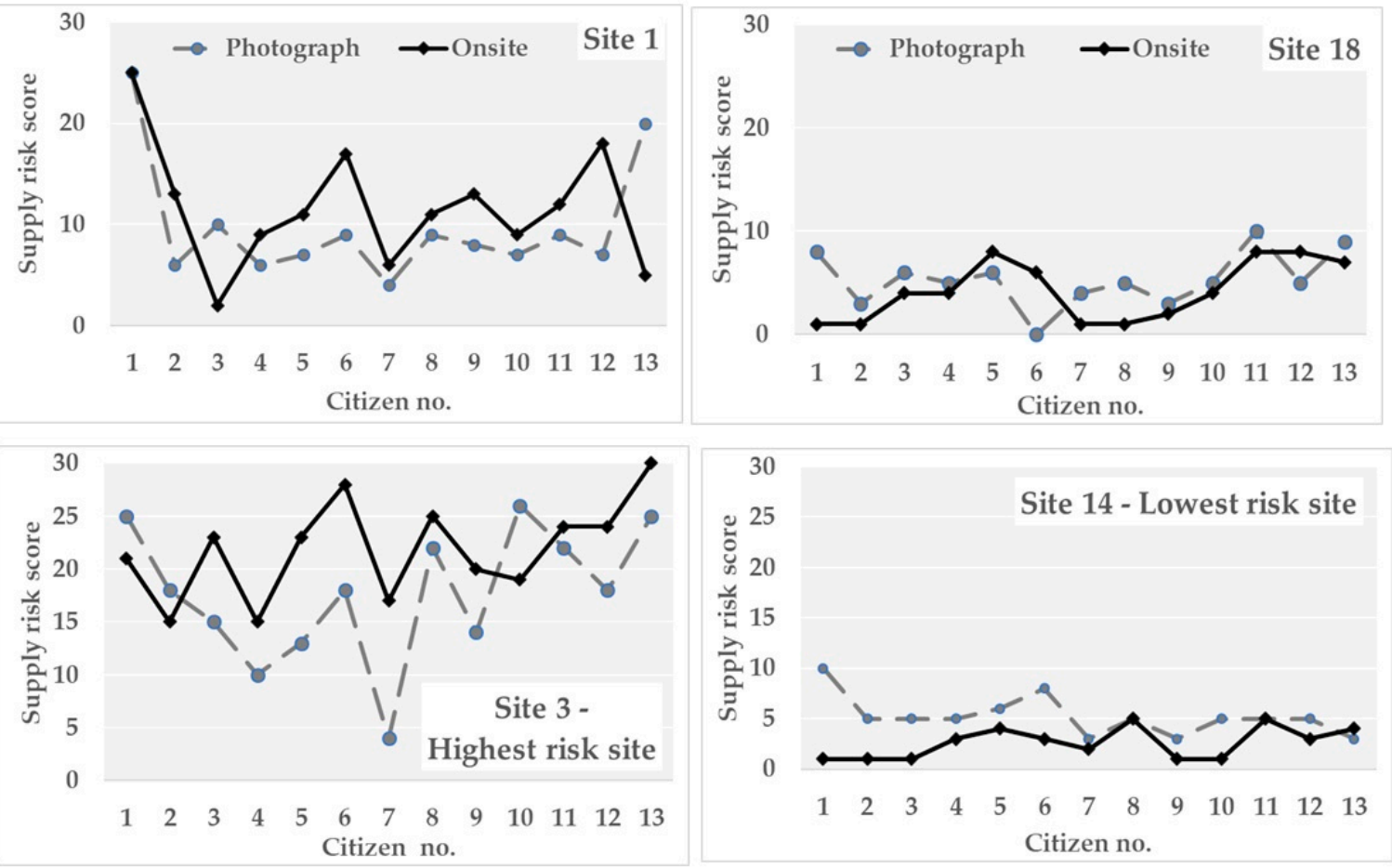

Figure 7. Comparison of risk attributed on-site (grey dashed line) with that from the photographic image (solid black line) per citizen.

Table 4. Spearman's rank correlation coefficients calculated per supply number to determine correlations between on-site and photographic inspection by the citizens.

\begin{tabular}{ccc}
\hline Supply Number & Correlation Coefficient-All Citizens & Correlation Coefficient-Without Outliers \\
\hline $\mathbf{1}$ & 0.36 (weak) & 0.66 (strong) \\
\hline $\mathbf{1 8}$ & 0.32 (weak) & 0.72 (strong) \\
\hline $\mathbf{3}$ & 0.48 (moderate) & $\mathrm{n} / \mathrm{a}$ \\
\hline $\mathbf{1 4}$ & -0.10 (very weak) & 0.22 (weak) \\
\hline
\end{tabular}

Figure 8 highlights that the citizens assessed Supplies 1 and 3 to have the highest average risk scores during both on-site and photographic inspection. In both cases, the risk assigned using the image of the water supply was lower than the risk assigned on-site. The reverse was found for the two lower risk sites indicating that questions 7 and 9 may have affected the overall supply risk score for higher risk supplies.

A total of four respondents answered all questions on the photographic SI form without ticking the box 'Unable to answer from image'. The remaining citizens selected the option 'unable to answer from image' most frequently for supplies 1 and 3 and predominantly for questions 6 and 8 (see Table 5). Question 4 relates to whether the drainage is adequate and questions 6 and 8 relate to sanitation infrastructure and other sources of pollution, both of which are within $10 \mathrm{~m}$ of the supply. Therefore, this indicates that, in most cases, respondents felt they were able to answer questions relating to the supply itself and the construction of the immediate borehole, however risks posed around the headworks and the catchment were unable to be answered by pictures. Should more pictures be provided this may alleviate this issue; one expert responded to question 6 that at least two pictures were required as there may be a latrine right where the picture had been taken. 


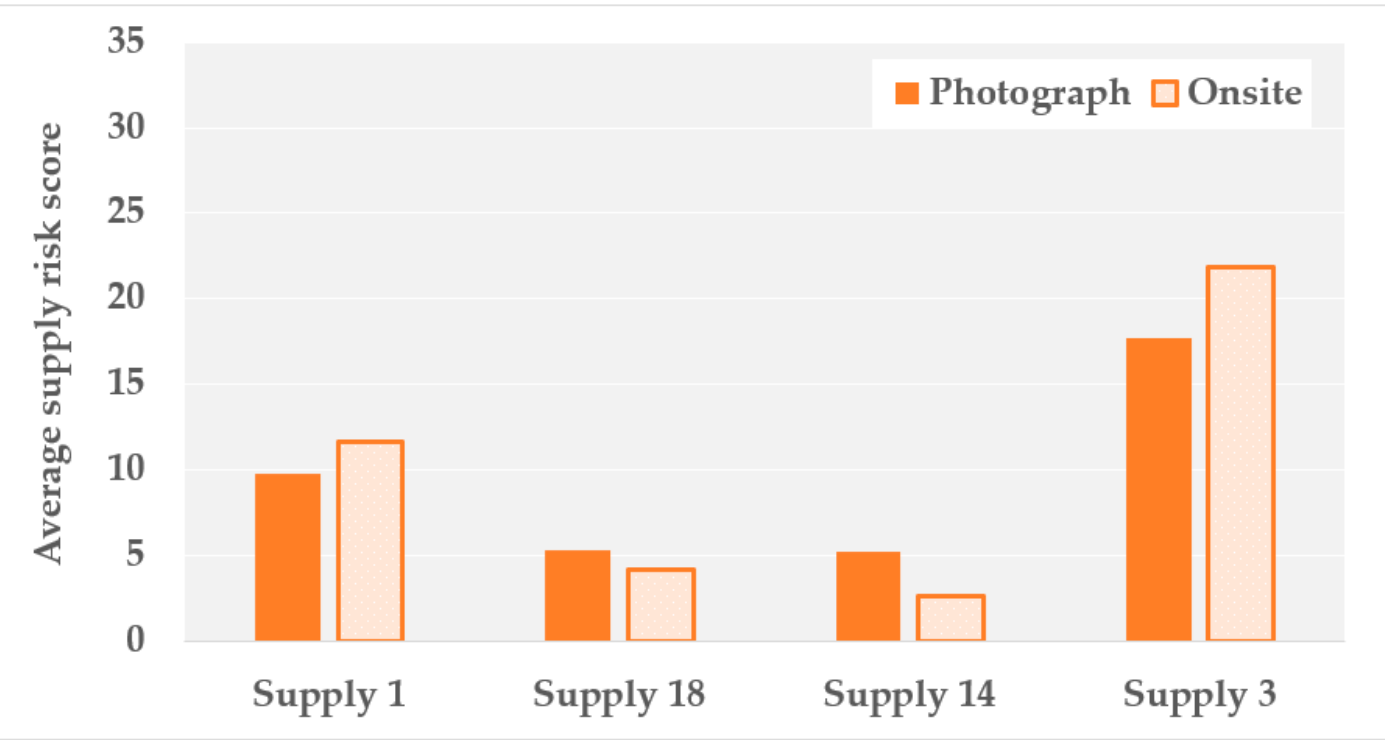

Figure 8. Average risk score assigned by citizens for each supply using on-site and photographic inspections.

Table 5. Number of times each question was assigned 'Unable to answer' by the citizens during the study using photographs (the number in brackets denotes frequency of responses by the 3 experts).

\begin{tabular}{cccccc}
\hline & Q1 & Q3 & Q4 & Q6 & Q8 \\
\hline Supply 1 & $1(1)$ & 1 & $4(1)$ & $4(3)$ & 8 \\
\hline Supply 18 & - & - & - & $6(3)$ & $1(2)$ \\
\hline Supply 3 (HR) & $(1)$ & 1 & 1 & $6(3)$ & $3(1)$ \\
\hline Supply 14 (LR) & - & - & - & $3(3)$ & $3(1)$ \\
\hline
\end{tabular}

There was a high level of agreement between the experts and the citizens regarding which questions could not be answered using the image. All experts indicated that they could not answer question 6 from an image for all supplies. Although not all of the citizens stated they could not answer question 6 from an image, this was the question they most frequently noted as being unable to answer. Note, questions 7 and 9 had been omitted from the questionnaire.

Expert responses from the borehole photographic inspections are provided in Table 6. There was a high level of agreement between how the citizens assigned risk both in the field and by using an image, and how the experts assigned risk. Although risk score did vary, even between the three experts, all participants (experts and citizens) responded following a similar trend. In all cases, experts and citizens assessed supply 1 to be of higher risk than supply 18, with supply 3 (the highest risk assigned by the group on-site) identified as the highest risk supply and supply 14 determined to be around the same level of risk as supply 18 .

Table 6. Borehole supply risk scores and "yes" responses as assigned by the SI experts.

\begin{tabular}{ccccccc}
\hline \multirow{2}{*}{ Supply No. } & \multicolumn{3}{c}{ Supply Risk Score } & \multicolumn{3}{c}{ No. “Yes" Responses } \\
\cline { 2 - 7 } & Expert 1 & Expert 2 & Expert 3 & Expert 1 & Expert 2 & Expert 3 \\
\hline $\mathbf{1}$ & 12 & 25 & 9 & 4 & 5 & 3 \\
\hline $\mathbf{1 8}$ & 6 & 5 & 5 & 2 & 1 & 1 \\
\hline $\mathbf{3}$ & 23 & 30 & 16 & 5 & 6 & 4 \\
\hline $\mathbf{1 4}$ & 5 & 5 & 5 & 1 & 1 & 1 \\
\hline
\end{tabular}




\section{Discussion}

This study aimed to assess the potential for citizen science to be employed in the SI process, with a view to improving the reach of SIs in countries with a high number of small supplies but limited resources to be able to effectively monitor them on a regular basis. By definition, SIs should be undertaken on-site [7,40]. However, in the interest of trying to achieve SDG 6-to achieve universal and equitable access to safe and affordable drinking-water quality and sanitation for all-and SDG 10 - to reduce inequality within and among countries-data gaps on safely managed drinking-water services urgently need to be filled to direct efforts to improve drinking-water services, to target those furthest behind, and to track changes in services over time [41]. The use of citizen science could also increase the potential interest in, and understanding of, water supplies by local people, especially pertinent to small drinking-water supplies which are often operated and maintained by non-technical people. We have investigated a number of factors to assess the suitability of citizens (non-experts in the field of SIs), to undertake SIs on small drinking-water supplies.

The notion of citizen science in the context of a closely regulated activity with strict compliance criteria, such as drinking-water quality monitoring, could be perceived as a complex one with regards to responsibilities. Some authors have included the concept of community-based management within their definition of citizen science [21], however in the context of drinking-water quality data, we propose that citizens would merely be used to increase the data volume and data quality. Authorities would still be expected to verify at least a sample of the results and would be responsible for acting on those results.

\subsection{The Perception of Risk by Non-Experts}

SIs are advocated by the WHO to identify hazards and risks to small drinking-water supplies. As previously reported, the interpretation of risk is an important factor when completing SI forms and can lead to variation in results even between professionals [8]. The perception of risk is an inherent part of decision-making processes [42]. In our study, the perception of the existence of risk aligned well between citizens recruited to complete the forms regardless of their technical background, i.e., which degree subject they were studying. There was also similarity in the risk level responses between citizens. These results are encouraging and confirm that although the initial SI forms published by WHO in 1997 were intended for use by qualified individuals [7], with appropriate support and verification steps in place, including validation from more qualified individuals, it is possible for citizens to contribute to producing useable data. It must be noted that the participants of the study all had a University level education and the impact of level of education on results was not tested during this study. This is a suggested area of further work.

There were two outliers in the results; one citizen with a background in auditing and one with a background in physical planning. The University entrance criteria for both subjects were the same, however Physical Planning is a science-based degree subject, whereas auditing is not. Neither individual had experience working with SIs, however the Physical Planning student has spent a significant period of time in rural settings so may have been more familiar with the types of supplies inspected. As these were the only two outliers, this could indicate that variations in SI risk responses were more influenced by the individual's perception of risk than the subject they studied. Indeed, it has been shown that direct personal experiences, for example life experience and affective processing, influences risk perception [43]. However, in the context of SIs this needs further exploration to make firm conclusions.

The introduction of assigning risk levels during SI is relatively new, with the original WHO forms just assigning the presence/absence of a risk [7]. Our study showed that the higher the perceived risk, the greater the variability in attributed risk scores. Other studies have shown that previous experience is a strong predictor of higher risk perception even after controlling for gender, origin, income, education and values [44]. 
Although variations in the actual risk scores were noted between the subjects the citizens studied, the risk profile of the supplies, i.e., those supplies which were deemed of higher or lower risk, followed the same trend. This indicates that in the case of using citizens to complete SIs, risk scores could be used to prioritise supplies requiring action using relative risk scores when reviewing a number of SIs inspected across a larger area.

Our study highlighted two characteristics regarding repeated SI. Firstly, the more inspections the citizens undertook, the more prepared they felt to assign risk confidently, but secondly, and conversely, they became increasingly desensitized to the risks. Repeating any process influences an individual's emotion [45]. Repetition can either strengthen or weaken an individual's risk perception at different levels depending on the number of times the process is repeated. An increasing effect of repetition on perceived risk with the first few repetitions and a decreasing effect with later repetitions has been identified in previous studies [46].

\subsection{Technical Challenges of Citizens When Completing SIs}

In agreement with previous studies [8,12], our results indicate the need to ensure that questions are unambiguous and that there is sufficient guidance, such as the provision of training, within the SI package.

An awareness of the different types of drinking-water supplies is required if non-technical individuals are to undertake SIs. The majority of the springs identified by the Water Officers, for inspection, were unprotected springs. This prompted discussion during the fieldwork regarding whether the spring SI form was appropriate when faced with this type of spring source. For SIs to be undertaken by non-technical persons there should be certainty about which is the correct form to use. Further clarification was not required for the more commonly used handpump boreholes, it was only the more remote and less commonly used spring supplies which raised questions about the applicability of the corresponding SI form. Although a form exists for spring supplies [36], it did not lend itself to the hazards encountered in the unprotected springs surveyed in the fieldwork setting of this study. These types of supplies would be classified as unimproved. Although rightly not promoted as a safe drinking-water supply by the WHO, it is estimated that 1 in 10 people (785 million) globally still lack basic services, including the 144 million who drink untreated surface water [47], with more than one in five people in 41 countries, many in Sub-Saharan Africa using unimproved drinking-water supplies for at least some part of the year [48]. It therefore seems highly appropriate that there is some sort of global assessment, management and guidance to highlight the hazards posed by unimproved supplies to users to plug the gap between the applicability of the spring form and these unimproved supplies. It should be noted that regardless of the lack of global guidance, countries are encouraged to adapt WHO-published SI forms to suit local situations.

\subsection{Remote SIs Using Images}

We found it very encouraging that when the citizens and the experts were asked to undertake the SI remotely using an image of the borehole water supplies, results correlated well with both the citizens' on-site and remote results, and the expert's remote results. Generally, both the citizens and experts were able to answer questions which related to the borehole headworks and structure of the supply. The questions which posed problems, to both experts and citizens, were those which required a survey of the surrounding area of the vicinity of the headworks and catchment. To ensure that remote answering is viable, several pictures, taken at different angles, would be needed to overcome this issue. Advanced technology such as drones are being used to monitor environmental indicators in collaboration with citizen science projects [49]. This type of approach could extensively expand the geographical spread of data collection in remote areas, although there are obvious cost barriers which would require consideration [49]

The SI is considered a robust tool for prioritizing investments as it accounts for supplies where either SI or water quality analysis might mischaracterize the supply. One challenge of undertaking SIs 
across the large number of small drinking-water supplies located in rural areas, is a lack of personnel, especially where inspectors are responsible for a large number of supplies over a wide geographical area or where they have other responsibilities. For example, the Drinking-Water Inspectorate of England and Wales report that in 2019 across England and Wales as a whole, just under two-thirds (64\%) of private (typically small) supplies have been risk assessed [50]. The international community has increasingly put forward citizen science to address the lack of water quality data and, provided certain factors such as good guidance and quality control are addressed, it can be successful [33].

It is imperative that in order to use this method of data collection, there is confidence in the accuracy of the process. Verification of at least a sample of the results of citizens by experts is a way to ensure this. If this can be shown to be done remotely then it opens up the possibility of citizen science being a useful tool for undertaking SIs. Citizen participation can provide a valuable source of data and monitoring which might be used as the first step in a selection process for doing an "expert" inspection on a small selection of supplies allowing resources to be saved.

Remote inspection, using images, could have huge benefits in terms of improving efficiency and can offer authorities and people managing a region a clearer picture of what is happening in the field, without a requirement for them to physically be on-site. This is undoubtedly a benefit where inspectors are overwhelmed by the number of supplies that need inspecting in their jurisdiction. In addition, the use of citizens to gather SI data increases awareness of the negative consequences of poor drinking-water management. This can lead to attitudinal changes among the public [51] with the long-term benefit of better management of small drinking-water supplies.

The materials required for citizens to conduct SIs and for remote expert verification are everyday items, e.g., a camera phone, internet connection. These are arguably less resource intensive than those needed for undertaking water quality sampling. As with water quality sampling, barriers to citizen science SIs include buy-in from participants, competence to assess risk and maintaining consistency of results. Both activities present challenges, with sampling requiring a methodological approach to sample taking, analysis and data recording, whereas risk assessment may be affected by the subjective interpretation of risk by the assessor, whether by a citizen or an expert [8].

\subsection{Areas for Further Work}

This study was useful to identify the initial potential use of SIs by citizens. Future studies should ensure the inclusion of individuals from varying demographic backgrounds including ages, educational levels and personal backgrounds, to identify the citizen science potential using a cohort who are more representative of the general population.

A future study would benefit from experts conducting SIs in the field to provide a direct comparison with the risk perception of citizens. Ideally expert assessment in the field would be conducted at the same time as by the citizens. If this is not possible consideration must be made to ensure there are no variations in actual risk, for example due to weather conditions or time of day.

\subsection{Limitations of the Study}

The results of this study were from a relatively small sample size and limited to two source types from one district. Before rolling out a large citizen science programme, further testing would be required with a larger sample.

Although all of this study's participants are inhabitants of Malawi, only $40.3 \%$ of the Malawian population were enrolled in secondary education in 2018. The students, therefore, have an above average level of education for the country as a whole [52]. As a result, certain challenges, such as literacy rates, which may have been highlighted through conducting the study.

The on-site SI data were collected by students all at the same time and therefore there is a small risk that risk perceptions could have been influenced by their peers. Actions were taken, including reminding the students that this was not a test and to assess individually, to mitigate this issue. This is a challenging limitation to overcome due to logistical issues of the remoteness of the supplies visited. 
Additionally, visiting supplies at different times of the day or on different days may lead to variations in conditions and could therefore lead to other, external factors influencing the variations in risk. In the same vein, it is logistically challenging for citizens and experts to survey the same supplies simultaneously to provide comparison with on-site SI scores, as experienced during this study.

\section{Conclusions}

The WHO Guidelines for Drinking-water Quality advocate the use of risk assessments, such as SIs, to identify hazards which may compromise the quality of small drinking-water supplies. The method was developed to be low cost, requiring little equipment, and to be useable by persons of low technical knowledge. The use of citizen science can help to overcome the personnel and resourcing issues which are commonly noted for small drinking-water supplies, and also offers a number of benefits especially where a sample of the inspections are verified by experts remotely. One of the challenges with citizen science is to achieve the same level of quality as on-site inspections. By conducting photographic inspections, we have identified a similarity in the risk profile assigned during on-site and photographic surveys. Our study has shown that with specific controls in place such as verification of at least a sample of the SIs by more experienced sanitary inspectors, and adequate guidance, citizen science could be a good option for extending the reach of SIs in a bid to reach the SDG targets. Any ambiguities in the wording of questions on the SI forms must be addressed, but it is possible for technical experts to verify SI results remotely via a photograph to support the prioritisation of intervention in cases where, common to small drinking-water supplies, the large number of supplies can overwhelm the managers and auditors of those supplies.

Supplementary Materials: The following are available online at http://www.mdpi.com/2079-9276/9/12/142/s1, a copy of the borehole and spring SI forms used during the surveys.

Author Contributions: Conceptualization, J.H., K.P. and R.K.; fieldwork and data collection, J.H., T.M. and R.K.; methodology, J.H.; writing — original draft preparation, J.H., K.P. and R.K.; writing-review and editing, J.H., R.K., T.M., K.O., D.J.L., R.M. and K.P.; funding acquisition, K.P., D.J.L. and R.M. All authors have read and agreed to the published version of the manuscript.

Funding: This research was funded by Research England as part of the government's aid strategy to further the sustainable development and welfare of developing countries (the Global Challenges Research Fund).

Acknowledgments: The authors would like to thank the students of The University of Malawi-The Polytechnic for their contributions and enthusiasm throughout this study. The authors would also like to thank the Ntcheu District Water Officers who facilitated and guided the researchers to the study locations. Contributions provided by the panel of SI experts, to whom the authors are thoroughly grateful, were an invaluable aspect of this research.

Conflicts of Interest: The authors declare no conflict of interest.

\section{References}

1. WHO. Drinking Water Fact Sheet; World Health Organization: Geneva, Switzerland, 2019. Available online: https://www.who.int/news-room/fact-sheets/detail/drinking-water (accessed on 1 October 2020).

2. UN. The Sustainable Development Goals Report 2020; United Nations: New York, NY, USA, 2020. Available online: https://unstats.un.org/sdgs/report/2020/The-Sustainable-Development-Goals-Report-2020.pdf (accessed on 21 October 2020).

3. WHO. Guidelines for Drinking-Water Quality, 3rd ed.; World Health Organization: Geneva, Switzerland, 2004. Available online: https://www.who.int/water_sanitation_health/publications/gdwq3/en/ (accessed on 1 October 2020).

4. WHO. Water Safety Plans in Eastern Europe, the Caucasus and Central ASIA; World Health Organization: Copenhagen, Denmark, 2014.

5. WHO; IWA. Global Status Report on Water Safety Plans: A Review of Proactive Risk Assessment and Risk Management Practices to Ensure the Safety of Drinking-Water; World Health Organization: Geneva, Switzerland, 2017.

6. European Commission. Proposal for a Directive of the European Parliament and of the Council on the Quality of Water Intended for Human Consumption. 2020. Available online: https:/eur-lex.europa.eu/legalcontent/EN/TXT/?uri=COM\%3A2017\%3A753\%3AFIN (accessed on 5 October 2020). 
7. WHO. Guidelines for Drinking-Water Quality: Surveillance and Control of Community Supplies, 2nd ed.; World Health Organization: Geneva, Switzerland, 1997. Available online: http://apps.who.int/iris/handle/ 10665/42002 (accessed on 5 October 2020).

8. Pond, K.; King, R.; Herschan, J.; Malcolm, R.; McKeown, R.M.; Schmoll, O. Improving Risk Assessments by Sanitary Inspection for Small Drinking-Water Supplies-Qualitative Evidence. Resources 2020, 9, 71. [CrossRef]

9. CAWST. Sanitary Inspection Forms. Available online: https://resources.cawst.org/forms/b93ac673/sanitaryinspection-forms (accessed on 1 October 2020).

10. Kelly, E.R.; Cronk, R.; Kumpel, E.; Howard, G.; Bartram, B. How we assess water safety: A critical review of sanitary inspection and water quality analysis. Sci. Total Environ. 2020, 718, 137237. [CrossRef] [PubMed]

11. WHO. Status of Small-Scale Water Supplies in the WHO European Region; Rickert, B., Samwel, M., Shinee, E., Kozisek, F., Schmoll, O., Eds.; WHO Regional Office for Europe: Copenhagen, Denmark, 2016. Available online: http://www.euro.who.int/_data/assets/pdf_file/0012/320511/Status-SSW-suppliesresults-survey-en.pdf?ua=1 (accessed on 30 September 2020).

12. King, R.; Okurut, K.; Herschan, J.; Lapworth, D.J.; Malcolm, R.; McKeown, R.M.; Pond, K. Does Training Improve Sanitary Inspection Answer Agreement between Inspectors? Quantitative Evidence from the Mukono District, Uganda. Resources 2020, 9, 120. [CrossRef]

13. Okotto-Okotto, J.; Wanza, P.; Kwoba, E.; Yu, W.; Dzodzomenyo, M.; Thumbi, S.M.; da Silva, D.G.; Wright, J.A. An Assessment of Inter-Observer Agreement in Water Source Classification and Sanitary Risk Observations. Exp. Health 2019, 11, 1-14. [CrossRef] [PubMed]

14. Yentumi, W.; Dzodzomenyo, M.; Sashie-Doe, K.; Wright, J. An assessment of the replicability of a standard and modified sanitary risk protocol for groundwater sources in Greater Accra. Environ. Monit. Assess. 2019, 191, 59. [CrossRef]

15. Kruger, L.E.; Shannon, M.A. Getting to know ourselves and our places through participation in civic social assessment. Soc. Nat. Resour. 2000, 13, 461-478.

16. Beza, E.; Steinke, J.; Van Etten, J.; Reidsma, P.; Fadda, C.; Mittra, S.; Mathur, P.; Kooistra, L. What are the prospects for citizen science in agriculture? Evidence from three continents on motivation and mobile telephone use of resource-poor farmers. PLoS ONE 2017, 12, e0175700. [CrossRef]

17. Christian, C.; Lintott, C.; Smith, A.; Fortson, L.; Bamford, S. Citizen science: Contributions to astronomy research. arXiv 2012, arXiv:1202.2577.

18. Domroese, M.C.; Johnson, E.A. Why watch bees? Motivations of citizen science volunteers in the great pollinator project. Biol. Conserv. 2017, 208, 40-47. [CrossRef]

19. Schröter, M.; Kraemer, F.; Mantel, M.; Kabisch, N.; Hecker, S.; Richter, A.; Neumeier, V.; Bonn, A. Citizen science for assessing ecosystem services: Status, challenges and opportunities. Ecosyst. Serv. 2017, 28, 80-94. [CrossRef]

20. Fraisl, D.; Campbell, J.; See, L.; Wehn, U.; Wardlaw, J.; Gold, M.; Moorthy, I.; Arias, R.; Piera, J.; Oliver, J.L.; et al. Mapping citizen science contributions to the UN sustainable development goals. Sustain. Sci. 2020, 15, 1-17. [CrossRef]

21. Conrad, C.C.; Hilchey, K.G. A review of citizen science and community-based environmental monitoring: Issues and opportunities. Environ. Monit. Assess 2011, 176, 273-291. [CrossRef] [PubMed]

22. Dickinson, J.L.; Shirk, J.; Bonter, D.; Bonney, R.; Crain, R.L.; Martin, J.; Phillips, T.; Purcell, K. The current state of citizen science as a tool for ecological research and public engagement. Front. Ecol. Environ. 2012, 10, 291-297. [CrossRef]

23. Pond, K.; Rees, G. Coastwatch UK: A public participation survey. J. Coast. Conserv. 2000, 6, 61-66.

24. Evans, C.; Abrams, E.; Reltsrna, R.; Roux, K.; Salmonsen, L.; Marra, P.P. The Neighborhood Nestwatch Program: Participant outcomes of a citizenscience ecological research project. Conserv. Biol. 2005, 19, 589-594. [CrossRef]

25. Lynam, T.; Jong, W.; Sheil, D.; Kusumanto, T.; Evans, K. A review of tools for incorporating community knowledge, preferences and values into decision making in natural resources management. Ecol. Soc. 2007, 12, 5-18. [CrossRef]

26. Conrad, C.; Daoust, T. Community-based monitoring frameworks: Increasing the effectiveness of environmental stewardship. Environ. Manag. 2008, 41, 356-358. [CrossRef] [PubMed] 
27. Karney, R.C. Poor water quality? Not in my backyard! The effectiveness of neighborhood pond associations in the protection and improvement of shellfish growing waters on Martha's Vineyard. J. Shellfish. Res. 2000, 19, 465-466.

28. Whitelaw, G.; Vaughan, H.; Craig, B.; Atkinson, D. Establishing the Canadian Community Monitoring Network. Environ. Monit. Assess. 2003, 88, 409-418. [CrossRef]

29. Royle, J.A. Modeling abundance index data from anuran calling surveys. Conserv. Biol. 2004, 18, 1378-1385. [CrossRef]

30. Abbott, B.W.; Moatar, F.; Gauthier, O.; Fovet, O.; Antoine, V.; Ragueneau, O. Trends and seasonality of river nutrients in agricultural catchments: 18 years of weekly citizen science in France. Sci. Total Environ. 2017, 624, 845-858. [CrossRef] [PubMed]

31. Thornhill, I.; Ho, J.G.; Zhang, Y.; Li, H.; Ho, K.C.; Miguel-Chinchilla, L.; Loiselle, S.A. Prioritising local action for water quality improvement using citizen science; a study across three major metropolitan areas of China. Sci. Total Environ. 2017, 584, 1268-1281. [CrossRef] [PubMed]

32. Wilson, N.J.; Mutter, E.; Inkster, J.; Satterfield, T. Community-Based Monitoring as the practice of Indigenous governance: A case study of Indigenous-led water quality monitoring in the Yukon River Basin. J. Environ. Manag. 2018, 210, 290-298. [CrossRef] [PubMed]

33. Brouwer, S.; Van der Wielen, P.W.J.J.; Schriks, M.; Claassen, M.; Frijns, J. Public Participation in Science: The Future and Value of Citizen Science in the Drinking Water Research. Water 2018, 10, 284. [CrossRef]

34. Wanda, E.M.; Manda, M.; Kushe, J.; Msiska, O.; Mphande, C.; Kamlomo, D.; Kaunda, J. Using citizen science approach to monitor water, sanitation and hygiene related risks in Karonga town, Malawi. Afr. J. Environ. Sci. Technol. 2017, 11, 304-323.

35. Gouveia, C.; Fonseca, A.; Câmara, A.; Ferreira, F. Promoting the use of environmental data collected by concerned citizens through information and communication technologies. J. Environ. Manag. 2004, 71, 135-154. [CrossRef]

36. WHO. Sanitary Inspection Package (Drinking-Water): Spring Source. Available online: https://www.who.int/ water_sanitation_health/water-quality/safety-planning/spring-source/en/ (accessed on 15 October 2020).

37. The Nation. Mpira Dam Dries up, Communities Suffer. 2018. Available online: https://www.mwnation.com/ mpira-dam-dries-up-communities-suffer/ (accessed on 1 October 2020).

38. World Vision. World Vision to Bring Water to Ntcheu. Available online: https://vimeo.com/284704052 (accessed on 1 October 2020).

39. RStudio Team. RStudio: Integrated Development for R. Rstudio; PBC: Boston, MA, USA, 2020. Available online: http://www.rstudio.com/ (accessed on 30 August 2020).

40. WHO. Guidelines for Drinking-Water Quality, 4th ed.; World Health Organization: Geneva, Switzerland, 2011. Available online: https://www.who.int/water_sanitation_health/publications/2011/dwq_guidelines/en/ (accessed on 1 October 2020).

41. Bain, R.; Johnston, R.; Slaymaker, T. Drinking water quality and the SDGs. NPJ Clean Water 2020, 3, 37. [CrossRef]

42. Williams, D.J.; Noyes, J.M. How does our perception of risk influence decision-making? Implications for the design of risk information. Theor. Issues Ergon. Sci. 2007, 8, 1-35. [CrossRef]

43. Van der Linden, S. On the relationship between personal experience, affect and risk perception: The case of climate change. Eur. J. Soc. Psychol. 2014, 44, 430-440. [CrossRef]

44. Öhman, S. Previous experiences and risk perception: The role of transference. J. Educ. Soc. Behav. Sci. 2017, 23, 1-10. [CrossRef]

45. Bornstein, R.F. Exposure and affect: Overview and meta-analysis of research, 1968-1987. Psychol. Bull. 1989, 106, 265. [CrossRef]

46. Lu, X.; Xie, X.; Liu, L. Inverted U-shaped model: How frequent repetition affects perceived risk. Judgm. Decis. Mak. 2015, 10, 219-224.

47. UNICEF; WHO. Progress on Household Drinking Water, Sanitation and Hygiene 2000-2017; Special Focus on Inequalities; United Nations Children's Fund (UNICEF) and World Health Organization: New York, NY, USA; World Health Organization: Geneva, Switzerland, 2019.

48. WHO. Safely Managed Drinking Water: Thematic Report on Drinking Water 2017; World Health Organization: Geneva, Switzerland, 2017. Available online: https://www.who.int/water_sanitation_health/publications/ safely-managed-drinking-water/en/ (accessed on 1 October 2020). 
49. Filipelli, G.; Anenberg, S.; Taylor, M.; van Geen, A.; Khreis, H. New Approaches to Identifying and Reducing the Global Burden of Disease from Pollution. GeoHealth 2020, 4. [CrossRef] [PubMed]

50. DWI. Drinking Water 2019 Private Water Supplies in England; Drinking Water Inspectorate: London, UK, 2020. Available online: http://dwi.defra.gov.uk/about/annual-report/2019/PWS-2019-England.pdf (accessed on 29 October 2020).

51. Wyles, K.J.; Pahl, S.; Holland, M.; Thompson, R.C. Can beach cleans do more than clean-up litter? Comparing beach cleans to other coastal activities. Environ. Behav. 2017, 49, 509-535. [CrossRef] [PubMed]

52. Education Statistics (EdStats) Country at a Glance-Malawi. Available online: http://datatopics.worldbank. org/education/country/malawi (accessed on 1 October 2020).

Publisher's Note: MDPI stays neutral with regard to jurisdictional claims in published maps and institutional affiliations.

(C) 2020 by the authors. Licensee MDPI, Basel, Switzerland. This article is an open access article distributed under the terms and conditions of the Creative Commons Attribution (CC BY) license (http://creativecommons.org/licenses/by/4.0/). 